\title{
Differential Brainstem Fos-Like Immunoreactivity after Laryngeal- Induced Coughing and Its Reduction by Codeine
}

\author{
Christian Gestreau, Armand Louis Bianchi, and Laurent Grélot \\ Département de Physiologie et Neurophysiologie, Centre National de la Recherche Scientifique Unité de Recherche \\ Associée 1832, Faculté des Sciences et Techniques Saint Jérôme, 13397 Marseille Cedex 20, France
}

\begin{abstract}
We used the expression of the immediate-early gene c-fos, a marker of neuronal activation, to localize brainstem neuronal populations functionally related to fictive cough (FC). In decerebrate, paralyzed, and ventilated cats, the level of Fos-like immunoreactivity (FLI) was examined in five groups of animals: (1) controls, sham-operated unstimulated animals; (2) coughing cats, including both animals in which FC was elicited by unilateral electrical stimulation of the superior laryngeal nerve (SLN) and (3) those in which FC was elicited by bilateral SLN stimulation; (4) stimulated-treated cats, in which bilateral SLN stimulation was applied after selective blockade of FC by codeine; and (5) codeine controls, sham-operated unstimulated cats subjected to administration of codeine. Fifteen brainstem structures were compared for numbers of labeled cells. Because codeine selectively blocks FC, brainstem nuclei activated specifically during FC were identified as regions showing
\end{abstract}

increased FLI after FC and significant reductions in FLI after FC suppression by codeine in stimulated-treated cats. In coughing animals, we observed a selective immunoreactivity in the interstitial and ventrolateral subdivisions of the nucleus of the tractus solitarius, the medial part of the lateral tegmental field, the internal division of the lateral reticular nucleus, the nucleus retroambiguus, the para-ambigual region, the retrofacial nucleus, and the medial parabrachial nucleus. FLI in all these nuclei was significantly reduced in stimulated-treated cats. Our results are consistent with the involvement of neurons overlapping the main brainstem respiratory-related regions as well as the lateral tegmental field and the lateral reticular nucleus in the neural processing of laryngeal-induced FC.

Key words: fictive cough; laryngeal afferents; antitussive drug; Fos-like immunocytochemistry; brainstem mapping; cat
Cough, a defensive reflex of the airways, is evoked by various stimuli to sensory receptors of the pharyngolaryngeal and tracheobronchial mucosa. Laryngeal cough, induced by activation of afferents in superior laryngeal nerves (SLNs), eliminates inhaled particles from the upper airway. Cough can be divided into an inspiratory phase characterized by an enhanced contraction of the diaphragm and abductor muscles of the upper airway, a compressive phase during which laryngeal adductor muscles close the glottis while expiratory muscles start to contract, and an expulsive phase that results from a sudden opening of the glottis and a powerful contraction of abdominal muscles (Korpas and Tomori, 1979).

Pharmacological studies have suggested the existence of a medullary cough center distinct from the respiratory centers (Bucher, 1958; Pozzeto and Traimer, 1962; Korecky and Palecek, 1964). Later experiments using electrical microstimulation, electrocoagulation, and local administration of antitussive drugs into medullary regions identified a cough center in the medial part of the dorsal medulla (Kasé et al., 1970; Kasé, 1980), an area overlapping the nucleus of the tractus solitarius (nTS) and adjacent structures. However, the precise location of second- and

\footnotetext{
Received May 27, 1997; revised Sept. 11, 1997; accepted Sept. 16, 1997.

We thank Drs. Myriem Yousfi-Malki and Jean-Jacques Puizillout for their help in developing histological technique, Dr. Federico Portillo for his involvement in preliminary experiments, Juliette Pio, Jocelyne Roman, and Michel Manneville for their technical assistance, and Drs. M. Roux and R. Shannon for their helpful suggestions.

Correspondence should be addressed to Dr. Christian Gestreau, Département de Physiologie et Neurophysiologie, Case 351, Faculté des Sciences Saint Jérôme, 13397 Marseille cedex 20, France.

Copyright (C) 1997 Society for Neuroscience $\quad 0270-6474 / 97 / 179340-13 \$ 05.00 / 0$
}

higher-order neurons generating cough remains unknown. Several electrophysiological studies have shown that cough motor circuits share common elements with respiratory centers (Jakus et al., 1985, 1987; Shannon et al., 1992; Oku et al., 1994; Gestreau et al., 1996), suggesting that cough and breathing might result from the activation of similar sets of neurons. However, all respiratory regions were not explored, and cough-related activities of neurons located outside respiratory-related regions were not examined. In an attempt to localize all brainstem regions containing neurons activated during SLN-induced fictive cough (FC), we used activity-driven Fos-like expression.

The expression of the nucleoprotein Fos, a product of the c-fos immediate-early gene, is widely considered a high resolution marker of neuronal activity (Dragunow and Faull, 1989; Morgan and Curran, 1991). Immunocytochemical detection of transcripts of the c-fos family genes (Fos and Fos-related antigens) has been used to map functional brainstem pathways in response to various stimuli (Erickson and Millhorn, 1991; Li and Dampney, 1992; Miller and Ruggiero, 1994; Yousfi-Malki and Puizillout, 1994; Wallois et al., 1995; Boissonade and Davison, 1996; Soulier et al., 1997).

In decerebrate and paralyzed cats, electrical stimulation of one or both SLNs elicits repetitive FC (Bolser, 1991; Grélot and Milano, 1991; Oku et al., 1994; Gestreau et al., 1996). Reflex activities were characterized by recording phrenic, abdominal, and hypoglossal nerve discharges. Brainstem Fos-like immunoreactivity (FLI) was quantified in coughing cats, sham-operated animals (controls), cats whose SLNs were stimulated while FC was impaired by codeine (stimulated-treated animals), and cats treated only with codeine. Regions specifically activated during 
FC exhibited an increase in FLI in coughing cats, as compared with controls, and a decrease in FLI in stimulated-treated cats, as compared with coughing animals.

A preliminary account of this work has been published previously (Gestreau et al., 1994).

\section{MATERIALS AND METHODS}

Animal preparation. Animal care was in agreement with the principles approved by the European Community as well as with French law. Experiments were performed on 22 adult cats of either sex weighing 2 to $4 \mathrm{~kg}$. Surgical procedures were the same for all animals. Cats were initially anesthetized by an intramuscular injection of $1.5 \mathrm{mg} / \mathrm{kg}$ of a mixture of alphaxalone and alphadolone acetate $(9$ and $3 \mathrm{mg} / \mathrm{ml}$, respectively) (Saffan, Pitman-Moore). After cannulation of the trachea and the left femoral vein and artery, a surgical level of anesthesia was maintained with a mixture of room air, oxygen (40\%), and halothane (1.5 to $2.5 \%$ ). In addition, local muscular infiltration of lidocaine and mepivacaine was performed at the surgical sites to alleviate any induction of Fos attributable to stimulation of nociceptors. Right and left SLNs and the right hypoglossal nerve were dissected free from surrounding tissues and placed on bipolar silver electrodes isolated with Parafilm and Vaseline. The cats were then placed prone in a stereotaxic frame and decerebrated at the midcollicular level. After dissection of a right C5 phrenic and a left iliohypogastric lumbar (L1, abdominal) rootlet, anesthesia was discontinued, and the animals were paralyzed with gallamine triethiodide (Flaxedil, Specia) (2 mg/kg/hr, i.v., supplemented as required) and artificially ventilated. Tidal volume and pump frequency were set to maintain an end-tidal $\mathrm{CO}_{2}$ around $3 \%$ to reduce the central inspiratory drive. These conditions reduce the basal expression of Fos (our unpublished observations). Histological processing was restricted to animals that maintained a mean arterial blood pressure between 90 and $120 \mathrm{~mm}$ $\mathrm{Hg}$ throughout the experiment. Rectal temperature was maintained between 36 and $38^{\circ} \mathrm{C}$ using a servo-controlled heating pad. Because the experiments were performed on paralyzed and ventilated cats, cough was present only as neural and not motor activity and is therefore called FC (Bolser, 1991; Grélot and Milano, 1991).

Recording and electrical stimulation. Activities were recorded from the hypoglossal and the intact C5 phrenic and iliohypogastric (L1) abdominal nerves using electrodes immersed in mineral oil. Under our experimental conditions (light hypocapnic hyperoxia), the reduced respiratory drive was evident as a weak augmenting ramp of phrenic activity and absent L1 activity. FC was elicited by repetitive electrical stimulation $(0.1-0.2 \mathrm{msec}$ pulses, $1-5 \mathrm{~V}, 2-5 \mathrm{~Hz}$ ) of the right or both SLNs. SLN shocks were applied at an intensity twice that required to elicit an inhibitory response in the phrenic nerve discharge. FC was characterized by an increase in duration, rate of rise, and amplitude of phrenic discharge, immediately followed by a large burst of L1 activity. A weak increase in hypoglossal discharge occurred during both phases of FC. Stimulation parameters were adjusted to minimize SLN-induced fictive swallowing indicated by short bursts of hypoglossal nerve activity (see Fig. 1).

The SLN was stimulated using three different paradigms. (1) In three cats, electrical shocks were applied to the right SLN for 30-40 min; (2) in three other cats, both SLNs were stimulated during three 30 min periods, each period being separated by $20 \mathrm{~min}$; and (3) in two additional cats, continuous stimulation of both SLNs was applied for $45 \mathrm{~min}$. In each paradigm, stimulation was interrupted for a few minutes when FC became difficult to elicit. SLN stimulation started 4.5 (2) or $6 \mathrm{hr}$ (1 and 3) after the end of surgery.

The pattern of codeine injection was based on results from preliminary experiments (three cats not included in the present report) and aimed to minimize drastic drops in blood pressure (Cox, 1994). Nine cats were treated with $17 \mathrm{mg} / \mathrm{kg}$ of codeine chlorhydrate diluted in $1.5 \mathrm{ml}$ of saline and administered in multiple injections over a period of $90 \mathrm{~min}$. All cats received the first injection of codeine $3.5 \mathrm{hr}$ before being killed and the last injection $15 \mathrm{~min}$ before the start of SLN stimulation. Times and routes of codeine administration were as follows. The drug was first injected intravenously ( $3 \mathrm{mg} / \mathrm{kg}$ slowly administered over $1 \mathrm{~min}) ; 20 \mathrm{~min}$ later, $3 \mathrm{mg} / \mathrm{kg}$ was injected intramuscularly; two other intramuscular injections ( $4 \mathrm{mg} / \mathrm{kg}$ each, every $30 \mathrm{~min}$ ) were made; and finally, $20 \mathrm{~min}$ later, a final intravenous injection $(3 \mathrm{mg} / \mathrm{kg})$ was given. In cats treated with codeine and in which laryngeal afferents were stimulated, bilateral SLN stimulation was applied continuously for $45 \mathrm{~min}$ [according to paradigm (3) above].

In the following text, "control" $(n=5)$ refers to untreated and unstimulated cats, "coughing" $(n=8)$ refers to untreated cats in which FC was induced by stimulation of the right $(n=3)$ or both SLNs $(n=5)$, "codeine-control" $(n=4)$ refers to unstimulated cats treated with codeine, and "stimulated-treated" $(n=5)$ refers to cats in which bilateral stimulation of SLN was applied but FC was impaired by codeine administration.

Tissue processing. All cats had identical survival times $(8 \mathrm{hr})$ after completion of surgery. Earlier deaths of control animals in preliminary studies resulted in a higher level of FLI, probably caused by the effect of anesthesia and/or surgery (Herdegen et al., 1991; Bonaz et al., 1994). Cats were perfused transcardially with 21 of $0.1 \mathrm{M} \mathrm{PBS,} \mathrm{pH} \mathrm{7.4,}$ containing $1000 \mathrm{U}$ heparin and $0.1 \%$ procaine, followed by 21 of $4 \%$ paraformaldehyde in phosphate buffer, $\mathrm{pH}=7.4$. The brainstem, and in two cases the cervical spinal cord $(\mathrm{C} 2-\mathrm{C} 7)$, were removed and post-fixed for $6 \mathrm{hr}$. Tissues were then successively cryoprotected at $4^{\circ} \mathrm{C}$ in solutions containing 10,20, and 30\% sucrose. Transverse sections were cut at $50 \mu \mathrm{m}$ using a cryostat and collected in PBS. Every fourth section was processed immunocytochemically for detection of Fos-like proteins.

Neural tissues from one or two stimulated animals were always processed simultaneously with those obtained from a control cat using separate test wells. To block nonspecific binding sites and facilitate tissue penetration, free-floating sections were first incubated for $1 \mathrm{hr}$ in PBS containing 2\% normal rabbit serum and $0.3 \%$ Triton X-100 (A solution). Afterward they were incubated for $24 \mathrm{hr}$ at $4^{\circ} \mathrm{C}$ in polyclonal Fos sheep antibody (Fos OA 11-824, CRB/Euromedex) (diluted 1:3000 in A solution). This primary antibody, raised against amino acids 2-17 of the human Fos protein, recognizes both Fos and Fos-related antigens. The use of this antibody rather than one specific to Fos protein could have contributed to the relatively high background observed in the present study (Dragunow and Faull, 1989). Sections from all experiments except those in which unilateral stimulation was applied (three cats) were processed with the same batch of primary antibody. After they were rinsed twice in PBS, sections were incubated for $1 \mathrm{hr}$ in biotinylated rabbit anti-sheep antiserum diluted (1:200) in PBS and then washed twice. Finally, sections were incubated in avidin-biotin-peroxidase complex $(1: 100,1 \mathrm{hr}$ ) (Vectastain ABC standard PK 4000, Vector Labs, Burlingame, CA). After three 10 min washes in PBS, the sections were processed for peroxidase using VIP substrate (SK 4600, Vector Labs) as the chromogen. After two washes in distilled water and then in PBS for at least $30 \mathrm{~min}$, sections were mounted on gelatin-coated slices, air-dried, dehydrated, cleared, and coverslipped in DePeX medium. Adjacent sections were counterstained with cresyl violet to delineate the location of nervous structures. In the present study, specificity was assessed by omission of either the primary or the secondary antibody. Such a procedure failed to produce any positive staining.

Determination of distribution and number of immunoreactive cell nuclei. Patterns of brainstem FLI were mapped, and Fos-positive neurons were counted in four groups of animals according to the experimental paradigms described above: control $(n=5)$, coughing $(n=8)$, codeine-control $(n=4)$, and stimulated-treated $(n=5)$ cats. Sections processed immunocytochemically for Fos-like proteins were examined with bright-field optics using a Polyvar microscope, drawn with a camera lucida, and photographed using black and white films (Kodak T-Max). For some brainstem structures, anatomical landmarks were determined using adjacent counterstained sections. Criteria used to select specific sections for quantification included (1) identification of the nucleus or subnucleus of interest on the section; (2) the absence of artifacts in the area; and (3) the same rostrocaudal level for sections from different animals. Fos-positive cell counting was performed with a Zeiss microscope and a video-scanning system (C2400, Hamamatsu) coupled to a Macintosh computer using appropriate software to digitize images (Digital Vision) and evaluate grain density (Biolab/ Piclab). Automatic counts were based on the average density of Fospositive cell nuclei relative to a given threshold. The appropriate threshold providing the best discrimination of target cells from background was set up from the first digitized image of the series. Then the same threshold was used for counting immunoreactive cells in the remaining digitized images, i.e., obtained from sections processed in parallel during immunocytochemistry. For the three cats stimulated unilaterally, cell counting was performed bilaterally in various brainstem structures. For each nucleus or subnucleus, four different sections were used to count FLI in both ipsi- and contralateral sides. For the remaining animals (coughing cats stimulated bilaterally, control, codeine-treated, and stimulated-treated), cell counting was performed 
unilaterally. An average number of Fos-positive cells per section of 50 $\mu \mathrm{m}$ was calculated in each structure from counts done from four different sections, except for two animals in which only three sections were available for the area postrema and the interstitial subdivision of the nTS. Mean values and SDs, expressed as mean \pm SD, were calculated for the various brainstem structures in each group. Nomenclature follows that of Kalia and Mesulam (1980) for the subdivisions of the nTS and that of Berman (1968) for the other pontomedullary structures.

Statistical evaluations. Statistical evaluation of our results was performed using computer software (Graphpad Instat). To assess the efficacy of the antitussive treatment with codeine, we compared the numbers of FC induced during 45 min of bilateral SLN stimulation in coughing $(n=2)$ and stimulated-treated $(n=5)$ cats using the Mann-Whitney test. Results are expressed as mean \pm SD. Histological data from unilaterally stimulated cats were collected with respect to the section number and laterality (ipsi- or contralateral to the stimulation). The numbers of Fos-positive cells induced in ipsi- versus contralateral brainstem structures were compared using a nonparametric paired test (Wilcoxon two-tailed). Because a different batch of antibodies was used to perform immunocytochemistry on brainstem sections from unilaterally stimulated cats, statistical comparisons with results from animals of the other groups were not possible. Instead, a one-way ANOVA was used for the latter to determine whether significant differences exist between mean numbers of Fos-positive cells counted in given brainstem areas. Post hoc analysis was used to determine which groups differed; $p$ values were corrected (Bonferroni method) to compensate for multiple comparisons. Differences were considered significant at $p<0.05$.

\section{RESULTS}

\section{Elicitation of fictive coughing}

Because in some animals SLN stimulation was interrupted for a few minutes when FC became difficult to elicit, the mean rate of FC production was calculated by dividing the total number of evoked FCs by the real duration of stimulation (i.e., $\leq 30-40$ $\mathrm{min}, \leq 45 \mathrm{~min}$, or $\leq 90 \mathrm{~min}$ ). In three cats, stimulation of the right SLN for 30-40 min elicited $57 \pm 9.9 \mathrm{FC}$ (range, 49-68), giving a mean rate of $1.5 \pm 0.2 \mathrm{FC} / \mathrm{min}$. In three other cats, bilateral stimulation of SLN applied for three $30 \mathrm{~min}$ periods elicited $267 \pm 139 \mathrm{FC}$ (range, 132-411), giving a mean rate of $3.5 \pm 1.4$ $\mathrm{FC} / \mathrm{min}$. In two additional cats, bilateral SLN stimulation applied continuously for 45 min elicited 142 and $116 \mathrm{FC} \mathrm{(129 \pm 18.4),}$ corresponding to a mean rate of $3.2 \pm 0.7$ coughs $/ \mathrm{min}$ (Fig. $1 \mathrm{~A}$ ). Codeine was administered in five other cats before bilateral SLN stimulation was applied continuously for $45 \mathrm{~min}$. The incidence of $\mathrm{FC}(8.8 \pm 11.1 \mathrm{FC}$; range, $0-27$; mean rate of $0.3 \pm 0.3 \mathrm{FC} / \mathrm{min})$ in codeine-treated animals was significantly less $(p<0.001)$ than in noncodeine-treated animals stimulated similarly (Figs. $1 B$, Fig. 2).

In addition to $\mathrm{FC}$, other reflexes were observed transiently at the onset of SLN stimulation, e.g., an increase in arterial blood pressure (20-30 $\mathrm{mm} \mathrm{Hg}$ above the control pressure) and a weak bronchoconstriction (increase in tracheal pressure). Salivation and occasional buccopharyngeal stages of swallowing were also elicited throughout the stimulation period. Codeine treatment did not affect salivation (data not shown), the transient changes in blood and tracheal pressures, and swallowing (Fig. 1B).

\section{Brainstem distribution of FLI}

Fos-like expression appeared within the nuclei of immunoreactive neurons as a blue-violet staining of variable intensity. Figure 3 illustrates the distribution of FLI in the brainstem of control, coughing, codeine-control, and stimulated-treated animals.

\section{FLI in control animals}

In control cats (sham-operated unstimulated animals, $n=5$ ), intense FLI was detected in the medial and inferior vestibular

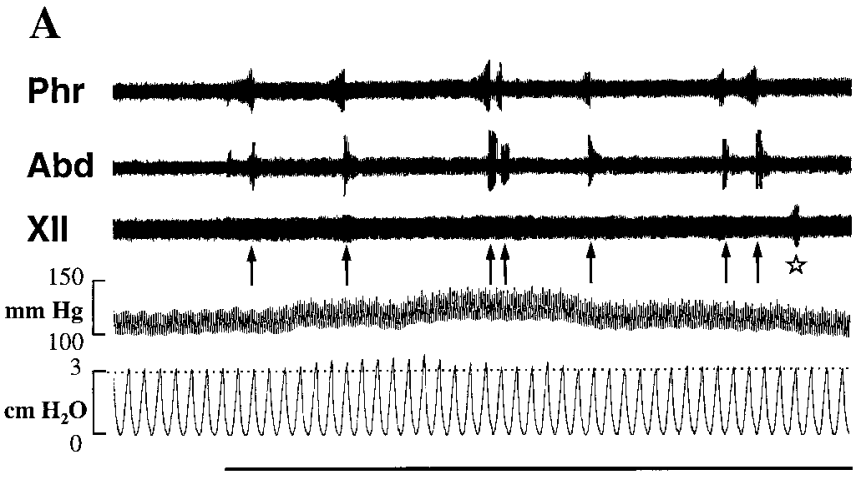

SLN

B

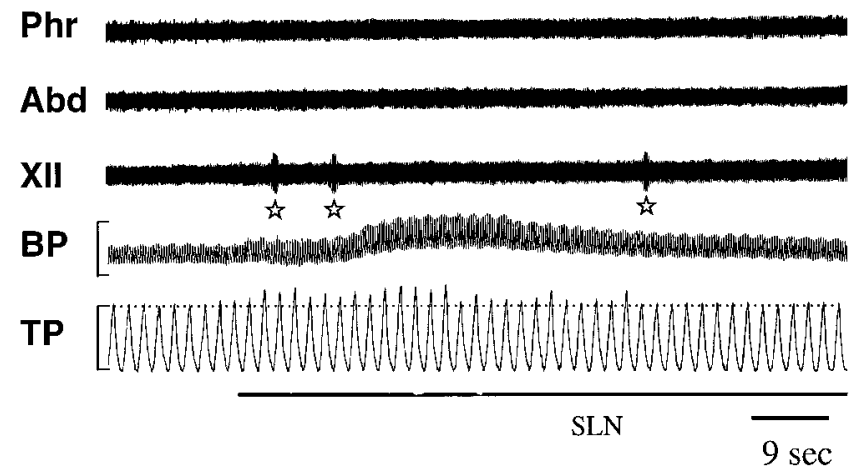

Figure 1. Effects of SLN stimulation (black bars below each panel) (0.2 msec pulses, $5 \mathrm{~V}, 4 \mathrm{~Hz})$ on phrenic $(P h r)$, iliohypogastric $(A b d)$, and hypoglossal $(X I I)$ nerve activities, and on arterial blood $(B P)$ and tracheal $(T P)$ pressures in coughing $(A)$ and stimulated-treated $(B)$ cats. In $A$, SLN stimulation induced multiple FCs (arrows) and transient hypertension and bronchoconstriction (slight increase in TP peaks above horizontal hatched line). In $B$, after the last intravenous injection of codeine given 15 min before the start of SLN stimulation (see Materials and Methods for details), FCs were abolished, whereas transient changes in BP and TP were not altered. Some buccopharyngeal stages of swallowing (stars) occurred regardless of the antitussive treatment. Stimulus artifacts were erased to improve legibility.

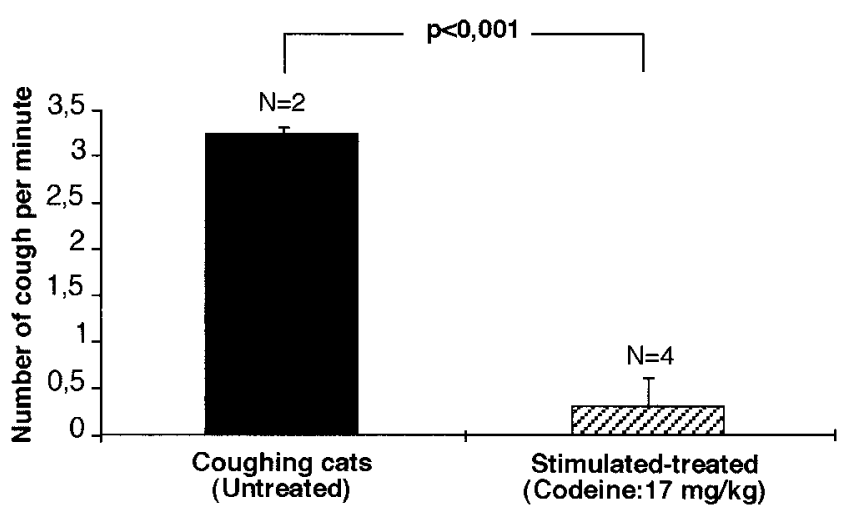

Figure 2. Antitussive effect of codeine on SLN-induced cough. Codeine significantly reduced the elicitation of FC.

nuclei (VN), and in the ventral part of the alaminar spinal trigeminal nucleus, i.e., the infratrigeminal nucleus (5SP). Sparse labeling was encountered in other regions throughout the rostrocaudal axis. A few labeled neurons were distributed within the nTS, typically confined to its dorsal division. Scattered labeled 
CONTROL
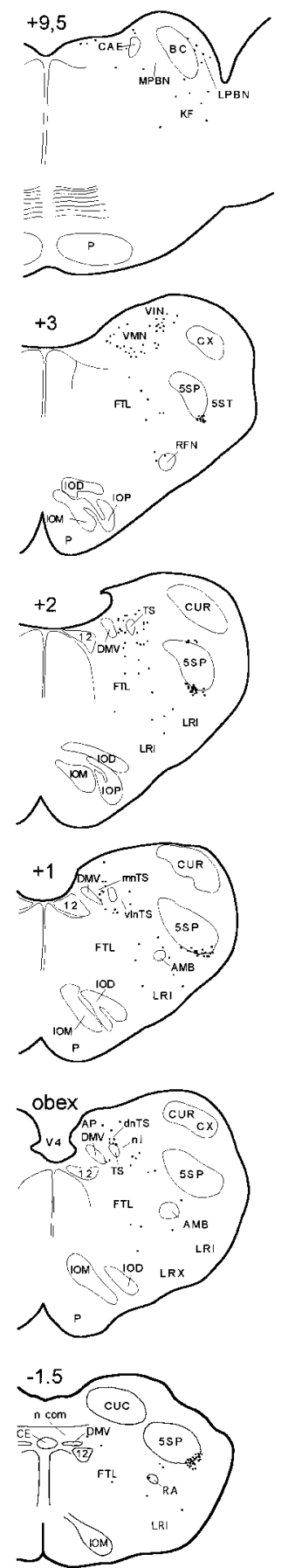

COUGHING
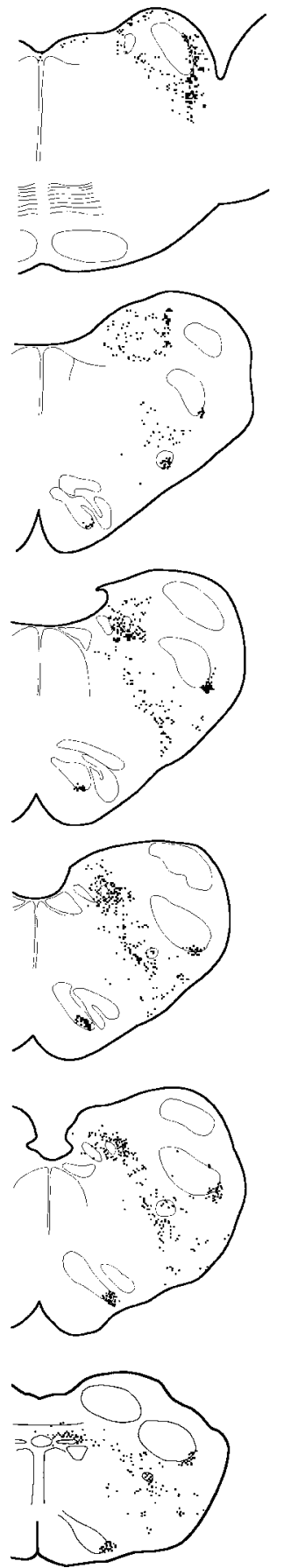

CODEINE-CONTROL
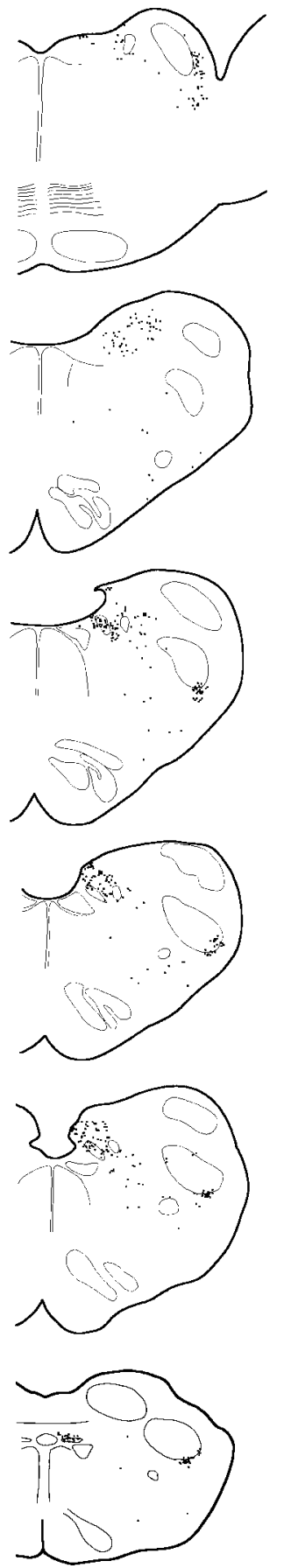
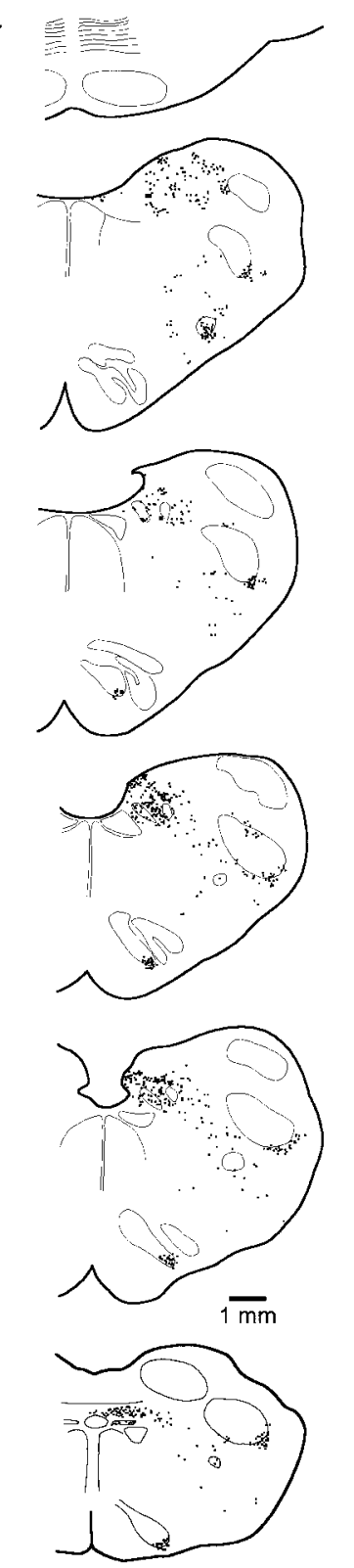

STIMULATED-TREATED

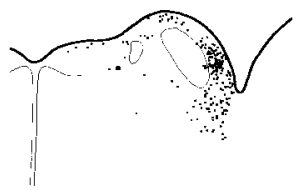

Figure 3. Distribution of brainstem FLI in transverse standardized hemisections through different rostrocaudal levels of control (unstimulated), coughing (262 SLN-induced coughs), codeine-control, and stimulated-treated (11 SLN-induced coughs) animals. Antitussive effect of codeine was associated with a decrease in FLI in dorsal, medial, and ventrolateral medulla and pons of the stimulated-treated animal. Each square represents one Fos-positive neuron. Rostrocaudal position relative to obex is indicated at top of drawing of each hemisection. 12, Hypoglossal nucleus; $5 S P$, 5ST, alaminar spinal trigeminal nucleus and tract; $A M B$, para-ambigual region; $B C$, brachium conjonctivum; $C A E$, locus caeruleus; $C E$, central canal; $C U C$, $C U R$, $C U X$, caudal, rostral, and external cuneate nucleus; DMV, dorsal motor nucleus of the vagus; FTL, lateral tegmental field; IOM, IOD, medial and dorsal accessory inferior olive; IOP, principal nucleus of the inferior olive; $K F$, Kölliker-Fuse nucleus; $L R I, L R X$, internal and external divisions of the lateral reticular nucleus; $N P B L, N P B M$, lateral and medial divisions of the parabrachial nucleus; $R A$, nucleus retroambiguus; $R F N$, retrofacial nucleus; $T S$, tractus solitarius; $d n T S, m n T S$, n.com, ni, vlnTS, dorsal, medial, commissural, interstitial, and ventrolateral subdivisions of the nucleus tractus solitarius ( $n T S)$; VIN, VMN, inferior and medial vestibular nuclei; $V 4$, fourth ventricle.

cells were also observed in the lateral tegmental field (FTL), the lateral reticular nucleus (LRN), the retroambiguus nucleus (RA), and the para-ambigual region (AMB). In the pons, a few neurons exhibiting a faint immunoreactivity were observed in the lateral parabrachial nucleus, the Kölliker-Fuse nucleus (KF), and the locus caeruleus (CAE). 

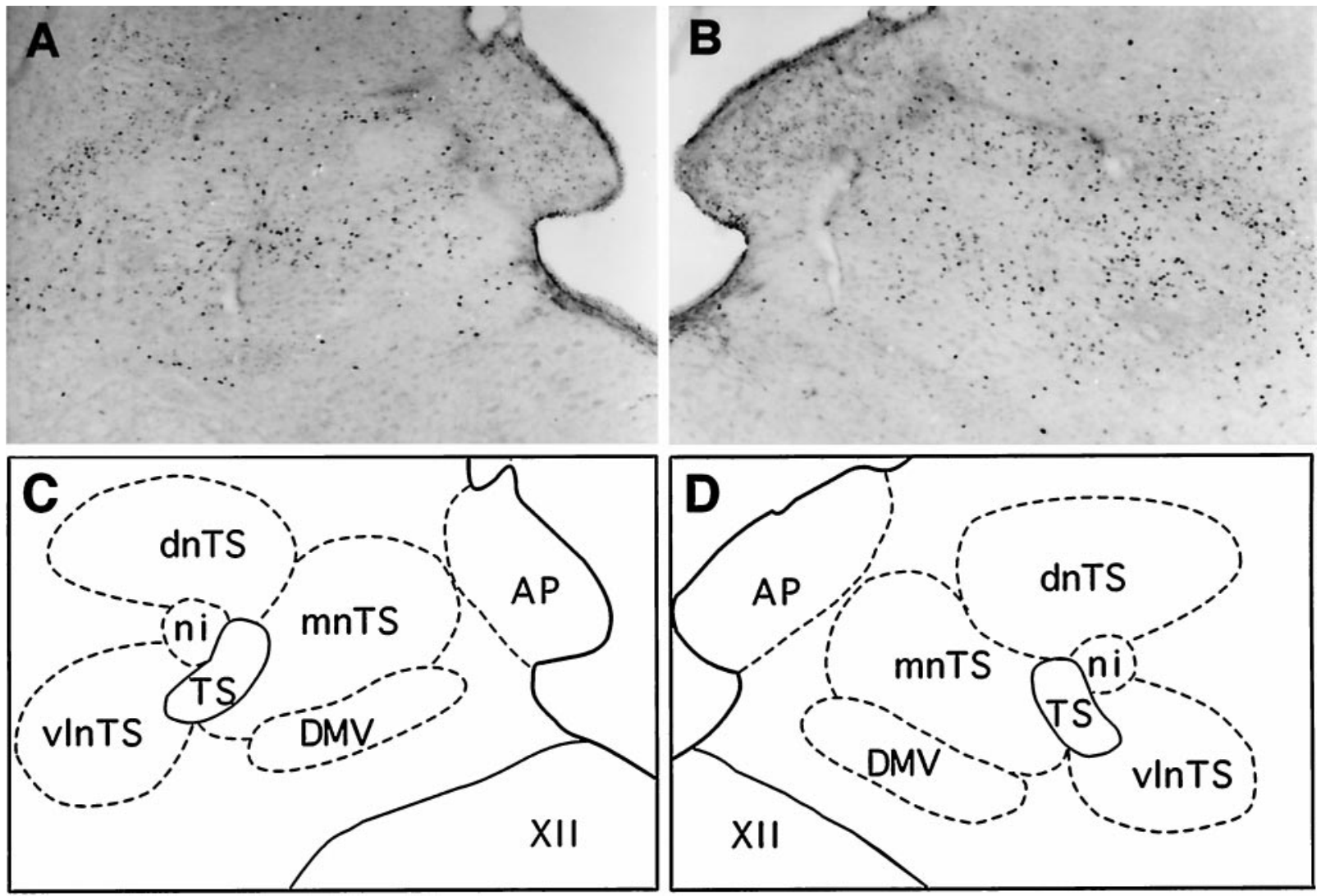

Figure 4. Bright-field photomicrographs illustrating patterns of FLI induced in the left $(A)$ and right $(B)$ dorsal vagal complex after FC elicited by stimulation of the right SLN. $A$ and $B$ are from the same transverse section. $C$ and $D$ are schematic drawings delineating dorsal medullary nuclei shown in $A$ and $B$, respectively. Note the increase in the number of Fos-positive cells in the ipsilateral nTS $(B)$ as opposed to the contralateral nTS $(A)$. Scale bar, $280 \mu \mathrm{m}$. Abbreviations are defined in legend to Figure 3.

\section{FLI in coughing animals: effect of unilateral SLN stimulation}

Intense FLI was detected bilaterally throughout the brainstem of animals whose right laryngeal afferents were stimulated. However, no Fos-labeled neurons were observed in the hypoglossal and facial nuclei. Medullary FLI extended mainly from $2.5 \mathrm{~mm}$ caudal to $4.5 \mathrm{~mm}$ rostral to the obex and included both dorsal and ventral areas, whereas FLI in the pons was restricted to the medial and lateral parabrachial nuclei (NPBM and NPBL, respectively), $\mathrm{CAE}$, and KF. In the dorsal and lateral medulla, dense clusters of FLI were seen in nTS, VN, and 5SP. Figure 4 illustrates the different distributions and numbers of Fos-positive cells within the dorsal medulla, contralateral (Fig. 4A) and ipsilateral (Fig. $4 B)$ to the stimulated (right) SLN. Ventrally, numerous labeled cells were distributed bilaterally along a radial axis extending from FTL, through the AMB to LRN, from $2.5 \mathrm{~mm}$ caudal to 2.6 $\mathrm{mm}$ rostral to the obex. FLI was most prominent in the medial part of FTL, dorsomedial to AMB. Only scattered Fos-positive nuclei were observed within multipolar cells of the nucleus ambiguus, whereas numerous small and round labeled cells were distributed ventromedially in the AMB. Between AMB and the ventral surface, FLI was restricted mainly to the internal division of LRN, i.e., the magnocellular part of LRN as identified by Ramon y Cajal (1909) or Brodal (1943). In addition, the retrofacial nucleus (RFN) exhibited dense Fos-positive cells; its ventral part (i.e., the sub-RFN) contained a cluster of immunoreactive cells from 2.8 to $3.4 \mathrm{~mm}$ rostral to the obex, whereas sparse Fos-positive cells were observed in its dorsal aspect. A compact core of Fos-positive neurons was present in the dorsal or the ventral part of the medial accessory inferior olive (IOM) from 1.5 $\mathrm{mm}$ caudal to $2.2 \mathrm{~mm}$ rostral to the obex. Caudally, RA displayed densely labeled cells.

The results of quantitative analysis of FLI within 15 brainstem structures, both ipsi- and contralateral to the stimulated SLN, are presented in Table 1. Stimulation of the right SLN resulted in more Fos-positive cells within ipsilateral nTS subdivisions and the ipsilateral IOM. In contrast, no differences were detected between the levels of FLI in the ipsi- and contralateral sides for the other brainstem regions (Table 1).

\section{FLI in coughing animals: effect of bilateral SLN stimulation}

We observed no differences between the distribution of FLI in coughing cats whose SLN afferents were bilaterally stimulated for three 30 min periods $(n=3)$ or for a single $45 \min$ period $(n=$ 2). Both patterns are thus described together. However, in two of the five coughing cats stimulated bilaterally (one for each stimulation paradigm), Fos-positive neurons were detected in the pallidus and obscurus raphe nuclei, but are not presented because of the inconstancy of this labeling. Representative distributions of Fos-positive neurons within the nTS of control and coughing cats are depicted in Figures 5 and 6 . The amount of FLI in the whole nTS was significantly greater $(p<0.05)$ than in controls (see Fig. 9). The most caudal division of the nTS, the commissural nucleus (n.com), contained numerous labeled neurons distributed mainly on both sides of the central canal from $2.5 \mathrm{~mm}$ caudal to the obex 
Table 1. Bilateral FLI counts in 15 brainstem structures of coughing cats in which electrical stimulation was applied only to the right SLN

Unilateral Stimulation of the right SLN

Ipsi Contra

$(n=3)$

\begin{tabular}{lcc}
\hline VN & $61 \pm 35$ & $64 \pm 31$ \\
5SP & $27 \pm 9$ & $27 \pm 11$ \\
IOM & $98 \pm 37^{*}$ & $18 \pm 7$ \\
FTL & $6 \pm 3$ & $6 \pm 4$ \\
nTS total & $201 \pm 25^{* *}$ & $127 \pm 34$ \\
n.com & $62 \pm 34^{*}$ & $44 \pm 26$ \\
dnTS & $37 \pm 10^{* *}$ & $21 \pm 8$ \\
mnTS & $42 \pm 16$ & $31 \pm 11$ \\
ni & $33 \pm 9^{* *}$ & $13 \pm 6$ \\
vlnTS & $28 \pm 12^{* *}$ & $18 \pm 7$ \\
AP & $4 \pm 4$ & $2 \pm 2$ \\
DMV & $6 \pm 3$ & $4 \pm 4$ \\
LRN & $18 \pm 5$ & $18 \pm 6$ \\
RA & $11 \pm 3$ & $10 \pm 2$ \\
AMB & $19 \pm 10$ & $16 \pm 9$ \\
RFN & $28 \pm 11$ & $27 \pm 11$ \\
CAE & $20 \pm 7$ & $22 \pm 9$ \\
KF & $50 \pm 26$ & $57 \pm 16$ \\
NPBL & $32 \pm 14$ & $33 \pm 11$ \\
NPBM & $9 \pm 2$ & $9 \pm 4$ \\
\hline
\end{tabular}

Values are expressed as mean \pm SD and correspond to mean numbers of labeled cells per structure and per hemisection. Significant $p$ values are represented by asterisks $(* p<0.05 ; * * p<0.01)$ and indicate increases in FLI in medullary nuclei ipsilateral to the stimulated nerve compared with the corresponding contralateral structures.

(Figs. 3, 5). FLI was enhanced in the dorsal aspect of the nTS (dnTS) but did not differ in its medial division (mnTS). Furthermore, neurons in the margin of the interstitial nucleus (ni) and within the ventrolateral division (vlnTS) of the nTS exhibited enhanced labeling (Fig. 6B). FLI increased in the IOM (Fig. 3). In contrast, no differences between control and coughing animals were observed in the VN, 5SP, area postrema (AP), and dorsal motor nucleus of the vagus (DMV). Enhancement of FLI was also observed in FTL, RA, AMB, and LRN (Figs. 3, 7). Interestingly, FLI within these nuclei had the same distribution as that in unilaterally stimulated cats (see above). The mean numbers of labeled neurons in the whole RFN increased ( $p<0.001)$ compared with values obtained in control cats (see Fig. 9). In the pons, FLI was detected at the level of NPBL, NPBM, and KF between 9.5 and $11 \mathrm{~mm}$ rostral to the obex. In these pontine regions, the expression of Fos-like proteins was enhanced (Fig. $8 B)$. No differences between control and coughing animals were observed in CAE. No Fos-labeled cells were detected in the pontine reticular formation. In the spinal cords of two coughing cats, we observed FLI in laminae I and II of the dorsal horn (C2-C5), but no FLI was detected in the phrenic motor nucleus (Lamina IX in C4-C6).

\section{FLI in codeine-control cats}

In addition to FLI already described in the brainstem of untreated control animals, all codeine-control cats exhibited enhanced FLI in the dorsal vagal complex (Figs. 3, 5C, 6C). Although more labeled neurons were detected in three nTS divisions (n.com, dnTS, and mnTS), FLI increased significantly only in AP ( $p<$ $0.05)$ and DMV $(p<0.01)$ (Fig. 9). Values obtained from other brainstem areas did not differ from those in untreated control cats (Fig. 9).

\section{FLI in stimulated-treated cats: comparison with codeine-control animals}

Compared with codeine-treated (unstimulated) cats, the mean number of Fos-positive neurons in the dorsal vagal complex did not change in AP or DMV. However, FLI increased in the total nTS (Fig. 9A), reflecting increases in n.com $(p<0.01)$, dnTS $(p<0.05)$, and mnTS $(p<0.05)$, but not in the ni and vlnTS (Fig. 9B). In ventral medullary regions, mean numbers of Fospositive neurons in RA, AMB, and LRN were low, similar to those in codeine-control animals (Fig. 7D), but greater in RFN $(p<0.01)$ (Fig. 9C). In the other medullary regions, FLI was enhanced in IOM $(p<0.05)$ and FTL $(p<0.05)$. In 5SP and $\mathrm{VN}$, the mean numbers of labeled neurons were similar (Fig. 9D). In the pons, numerous labeled cells were observed (Fig. $8 D$ ), and the mean numbers increased in NPBL $(p<0.01)$ and $\mathrm{KF}(p<$ 0.05), but were similar in NPBM and CAE (Fig. 9E).

\section{FLI in stimulated-treated cats: comparison with coughing animals}

Compared with coughing animals, FLI was less in ni $(p<0.05)$ and vlnTS $(p<0.01)$ (Figs. 6, 9B), similar in n.com (Fig. 5), and greater in the other two nTS subdivisions (dnTS and mnTS, $p<$ 0.05 ) (Figs. 6, 9B). FLI was less in all nuclei of the ventral medulla ( $p<0.01$ for RA, AMB, and LRN, and $p<0.05$ for RFN) (Fig. $9 C)$. Nevertheless, the cluster of FLI in the ventral aspect of RFN was still observed in stimulated-treated cats (Fig. 3). In the other medullary regions, the level of FLI was similar in IOM but reduced $(p<0.01)$ in FTL (Fig. 9D). In the pons, mean numbers of labeled cells were similar in NPBL, KF and CAE, but less $(p<$ 0.01) in NPBM (Fig. 9E).

\section{DISCUSSION}

This is the first study to identify brainstem neurons exhibiting Fos-like expression after FC elicited by stimulation of laryngeal afferents. Electrical stimulation of SLN, unlike mechanical stimulation of upper airways (Korpas and Tomori, 1979), elicits repeated and frequent coughs. In addition, use of decerebrate, paralyzed ventilated cats avoids Fos-like expression induced by sensory feedback, stress and/or arousal mechanisms, or modifications caused by anesthetic agents. However, as a general limitation of the method, all neurons activated during a given motor act do not necessarily express Fos (Hunt et al., 1987). This is obvious in our study because hypoglossal and phrenic motoneurons did not exhibit FLI.

\section{FLI patterns in coughing versus control animals}

FLI was observed in the brainstem of both control and coughing cats but was greatly enhanced in selective nuclei of the latter. In control animals, a low level of FLI was detected in most brainstem regions. Nevertheless, all animals exhibited robust FLI in VN and 5SP, a result similar to that reported in decerebrate cats by Miller and Ruggiero (1994), possibly resulting from surgically induced nociceptive inputs (Bereiter et al., 1994).

FC caused large increases in FLI in various areas, including several nTS subdivisions and regions of the ventrolateral medulla. Results from unilateral stimulation, demonstrating an enhancement of FLI in the ipsilateral nTS, are in good agreement with a prominent ipsilateral projection of laryngeal afferents in the dorsal medulla (Kalia and Mesulam, 1980; Lucier et al., 1986). A close correspondence was observed between the FLI pattern within the nTS and the established projection sites of SLN sen- 


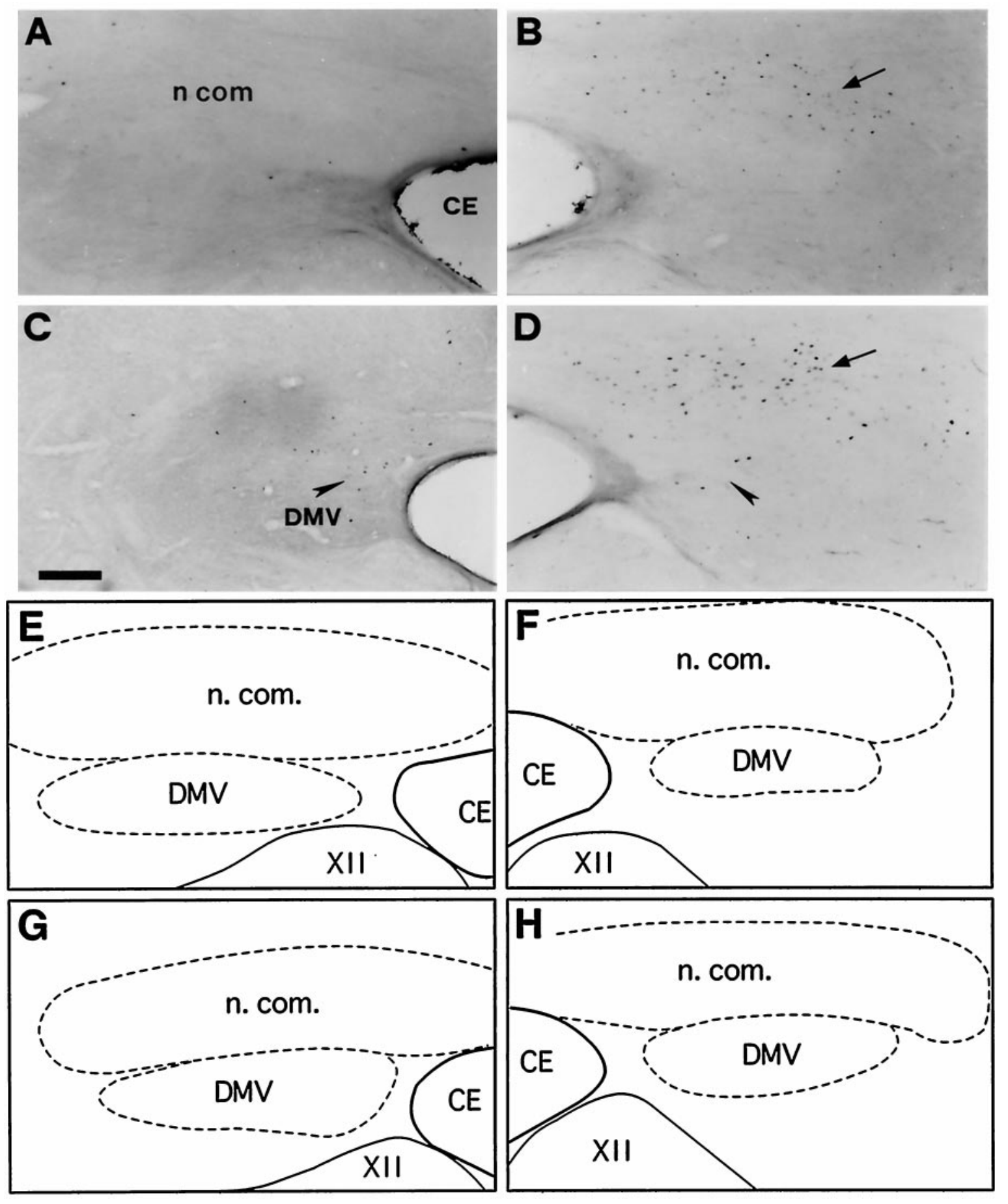

Figure 5. Bright-field photomicrographs of transverse sections illustrating FLI in the left $(A, C)$ and right $(B, D)$ commissural subdivision $(n$ com $)$ of the nTS. Control $(A)$, coughing $(B)$, codeine-control $(C)$, and stimulated-treated $(D)$ cats. FLI was induced in n.com of the two cats subjected to SLN stimulation whether or not they were treated with codeine (arrows in $B$ and $D$ ). Codeine induced a few Fos-positive neurons in the dorsal motor nucleus of the vagus nerve $(D M V)$ (arrowheads in $C$ and $D) . E, F, G$, and $H$ are schematic drawings of dorsal medullary nuclei shown in $A, B, C$, and $D$, respectively. Outlined structures indicate selected areas in which labeled cells were counted. Scale bar, $220 \mu \mathrm{m}$. CE, Central canal; XII, hypoglossal nucleus.

sory fibers. Thus, Fos-positive nTS neurons can be viewed as second-order neurons of the cough reflex arc. Although some SLN afferents project to 5SP (Lucier et al., 1986), we failed to find enhanced FLI in 5SP after SLN stimulation.

Laryngeal afferents do not project directly to the bulbar reticular formation, the ventrolateral medulla, or the pons. Fos- positive neurons overlapping these areas were thus likely polysynaptically activated and may correspond to higher-order neurons in the cough network. Because all of these areas exhibited a bilateral (and not enhanced ipsilateral) FLI after unilateral SLN stimulation, our results suggest that second-order nTS neurons distributed integrated information to both sides of the medial and 

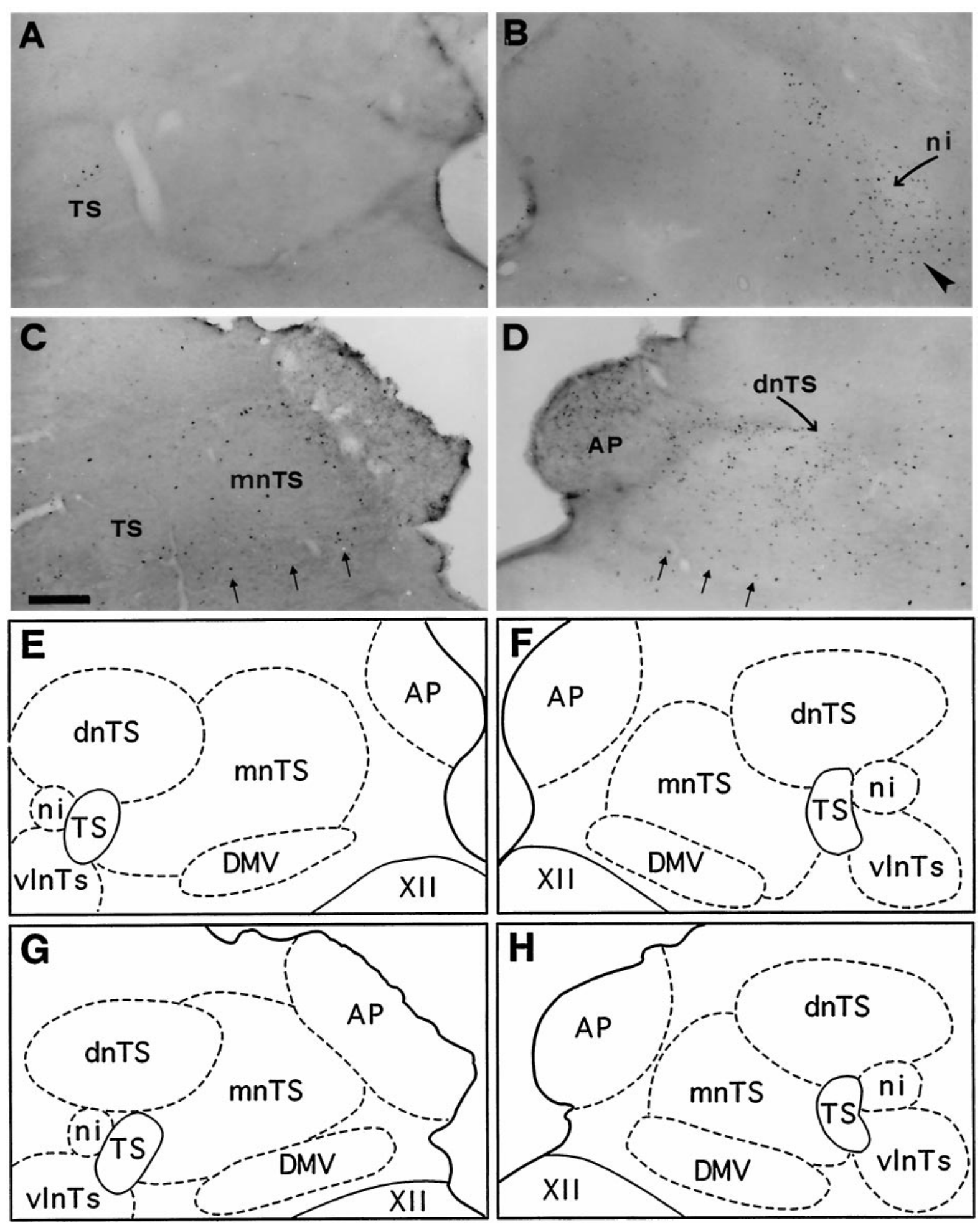

Figure 6. Bright-field photomicrographs of transverse sections illustrating FLI in the dorsal vagal complex (nTS, AP, and DMV) of medulla. Control $(A)$, coughing $(B)$, codeine-control $(C)$, and stimulated-treated $(D)$ cats. Note dense labeling in the interstitial (ni, curved arrow) and ventrolateral (arrowhead) subdivisions of the nTS observed only in B. Codeine induced sparse Fos-positive neurons in AP, DMV (three small arrows), and mnTS of codeine-control cat $(C)$. Similar FLI was also observed in AP and DMV of the stimulated-treated $(D)$ cat, associated with an increase in Fos-like expression in the dnTS and mnTS. $E, F, G$, and $H$ are schematic drawings of dorsal medullary nuclei shown in $A, B, C$, and $D$, respectively. Outlined structures indicate selected areas in which labeled cells were counted. Scale bar, $300 \mu \mathrm{m}$. Abbreviations are defined in legend to Figure 3.

ventral medulla. This may be achieved by axon collaterals, as demonstrated anatomically for some nTS neurons in the cat (Otake et al., 1989). In contrast, FLI in IOM may be explained by a heavy ipsilateral projection from laryngeal afferents via a paucisynaptic pathway. However, the functional role of the neuronal activation of IOM is unclear. 

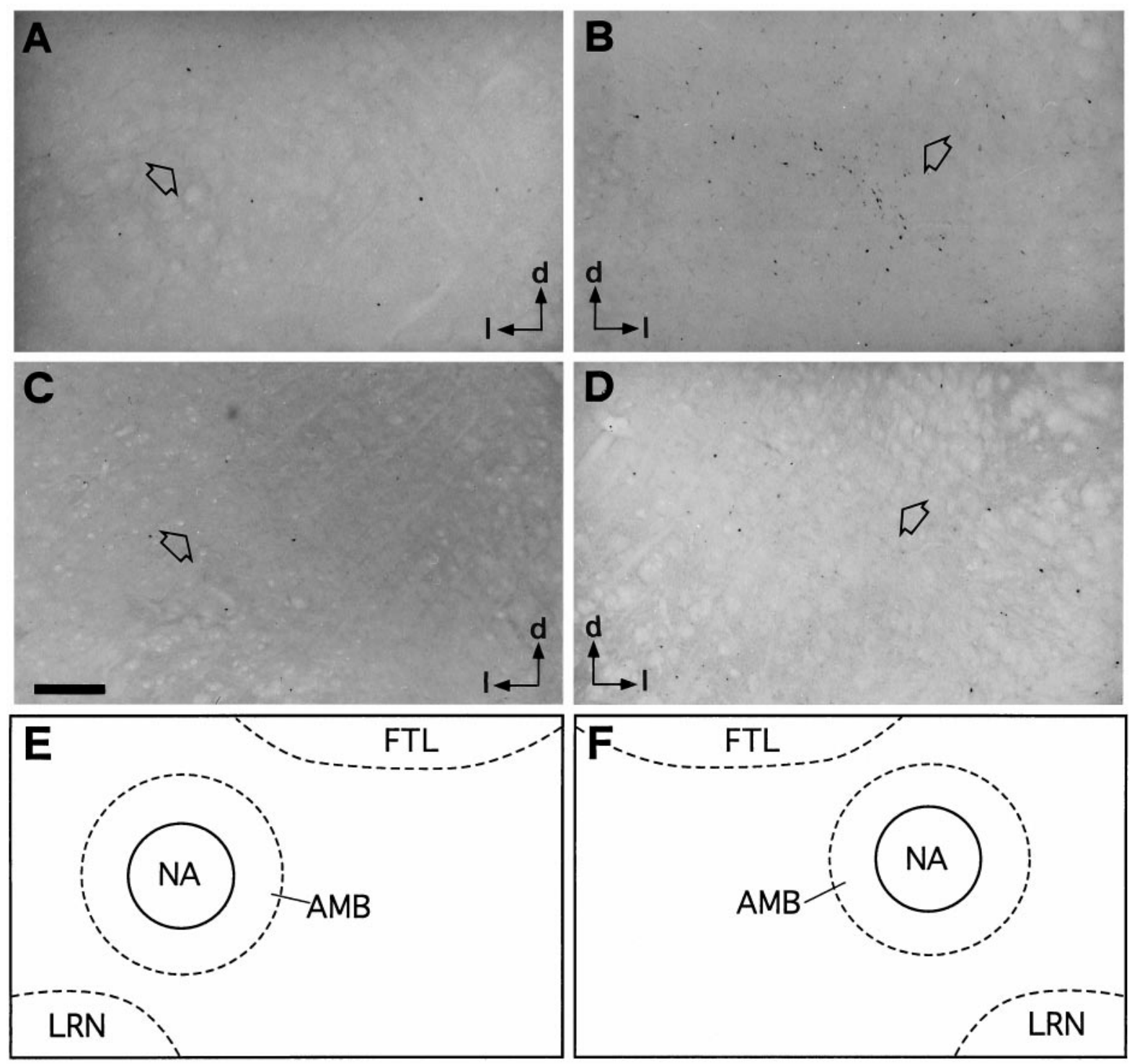

Figure 7. Bright-field photomicrographs of transverse sections illustrating FLI distribution in the ventral medulla overlapping the AMB and the nucleus ambiguus. Control $(A)$, coughing $(B)$, codeine-control $(C)$, and stimulated-treated $(D)$ cats. Open arrows point to the nucleus ambiguus. Arrows indicate the dorsal $(d)$ and lateral $(l)$ directions. Note in $B$ dense labeling ventromedial to the nucleus ambiguus. $E$ and $F$ are schematic drawings delineating the para-ambigual region $(A M B)$ (hatched line), including the nucleus ambiguus (NA) (continuous line) shown in $A$ and $B$, respectively. Similarly, $E$ and $F$ also match $C$ and $D$. Outlined structures indicate selected areas in which labeled cells were counted. Scale bar, $200 \mu \mathrm{m}$. Abbreviations are defined in legend to Figure 3.

\section{Significance of reduced FLI in stimulated-treated cats}

Both FC and FLI decreased in stimulated-treated animals. Reductions in FLI were especially evident in ni, vlnTS, the reticular formation (FTL and LRN), the ambigual complex (RA, AMB, and RFN) and NPBM. Tentatively, one can ascribe this FLI reduction to codeine-induced blockade of neurons forming the cough network. However, other opioid agonists, such as morphine, can reduce Fos-like expression in the CNS after nociceptive stimuli (Presley et al., 1990; Gogas et al., 1991; Hammond et al., 1992; Abbadie and Besson, 1993; Tölle et al., 1994; Ebersberger et al., 1995). If nociceptive SLN afferents had been activated and evoked FLI in coughing cats, the analgesic properties of codeine could explain this FLI reduction. Although we cannot exclude a contribution of pain pathways in induction of FLI in coughing cats, our results do not support this hypothesis. No differences were seen between levels of FLI in 5SP induced in the ipsilateral as opposed to the contralateral side in unilaterally stimulated cats, and in the control unstimulated animals compared with the stimulated ones. Because FLI induction in 5SP did not exceed that in controls, presumably nociceptive laryngeal afferents terminating in 5SP (Lucier et al., 1986) may have not been activated by SLN stimulation. In addition, codeine failed to reduce FLI in brainstem nuclei implicated in pain integration (5SP, n.com, and NPBL) (Lantéri-Minet et al., 1994). Thus, the marked FLI reduction observed in stimulated-treated cats likely resulted from the antitussive properties of codeine rather than its analgesic properties.

In codeine-control cats, FLI was enhanced in the dorsal vagal complex. Codeine may have induced FLI via a blood-borne route. An overdose of codeine activates the emetic reflex via AP (Borison, 1989). FLI in the DMV could have been caused by central activation of preganglionic vagal neurons by codeine (Kromer, 

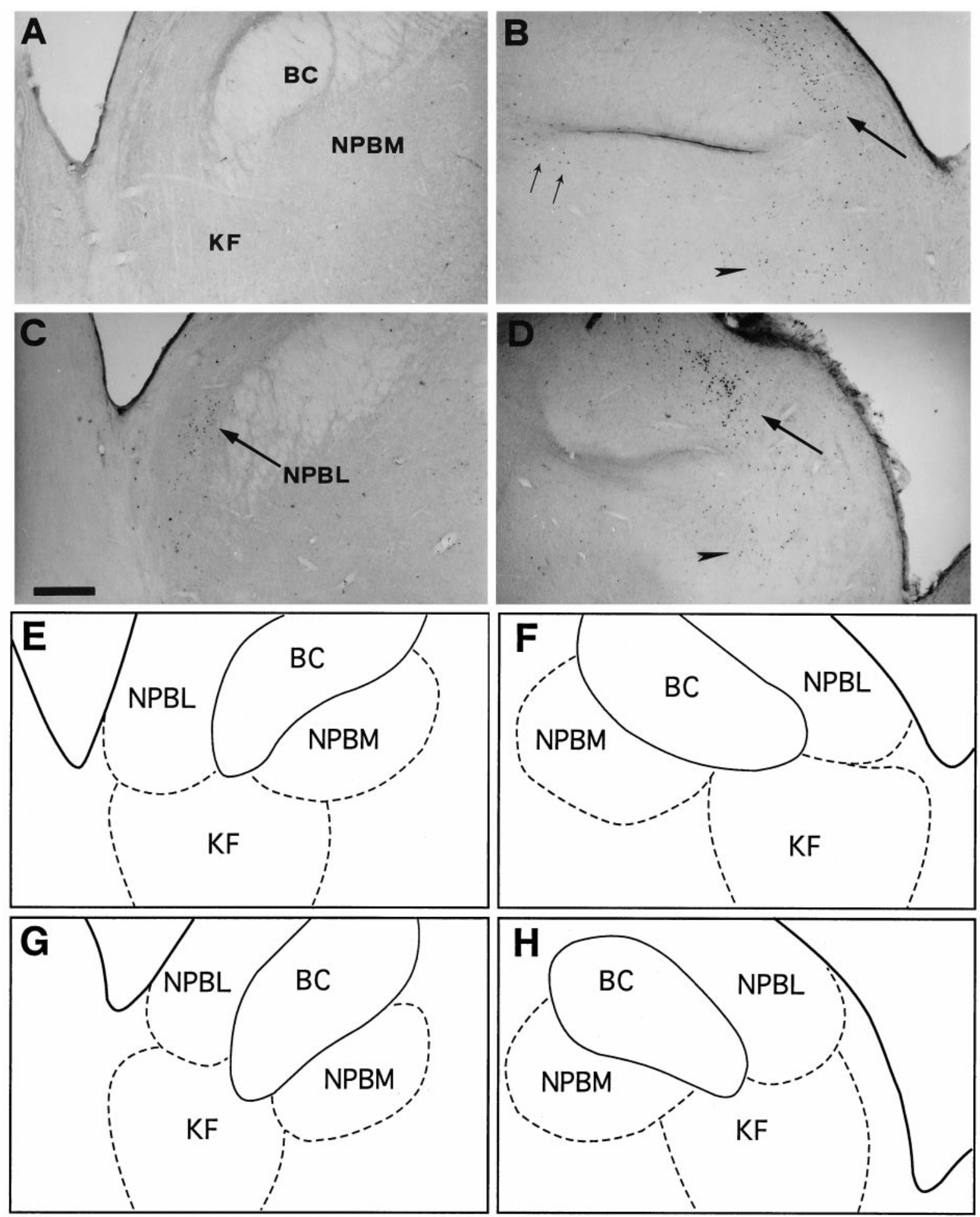

Figure 8. Bright-field photomicrographs of transverse sections depicting FLI distribution in the dorsolateral pons. Control $(A)$, coughing $(B)$, codeine-control $(C)$, and stimulated-treated $(D)$ cats. SLN stimulation induced dense FLI in NPBL (large arrows) and KF nucleus $($ arrowhead) of the two stimulated cats $(B, D)$. FLI evoked in NPBM (two small arrows) of coughing cat $(B)$ decreased after codeine administration $(D)$. $E, F$, $G$, and $H$ are schematic drawings of pontine nuclei shown in $A, B, C$, and $D$, respectively. Outlined structures indicate selected areas in which labeled cells were counted. Scale bar, $600 \mu \mathrm{m}$. Abbreviations are defined in legend to Figure 3.

1988). Alternatively, hypotension resulting from intravenous injection of codeine (Cox, 1994) could explain FLI observed in the dorsal vagal complex (Chan and Sawchenko, 1994; Li and Dampney, 1994).
Codeine treatment before SLN stimulation selectively decreased FC, yet marked FLI was still induced within n.com, mnTS, dnTS, IOM, the ventral part of RFN, KF, and NPBL. Although the latter structures may be involved in FC generation, 
A
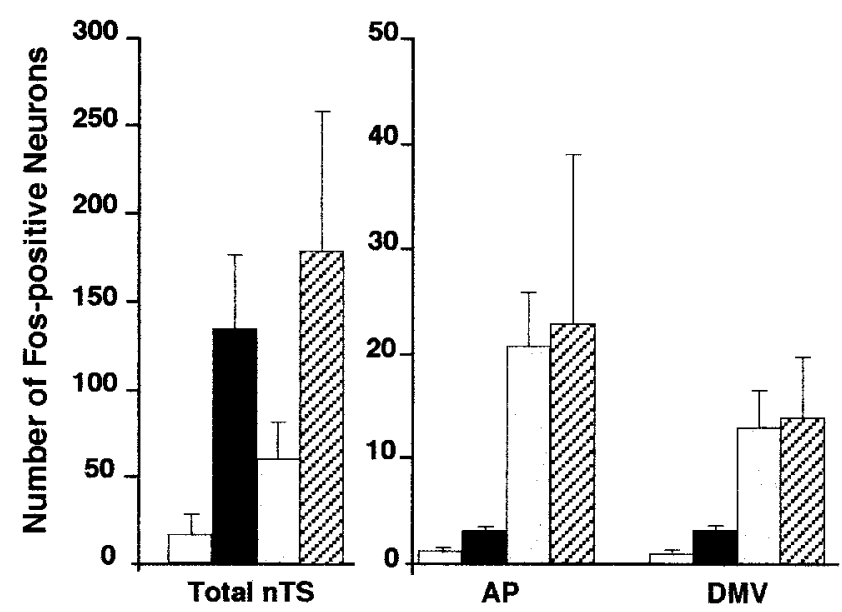

C

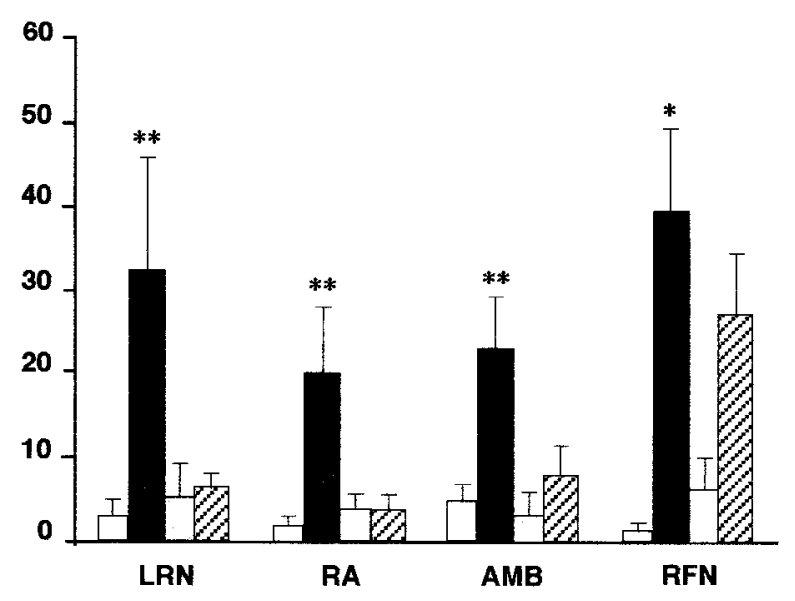

E

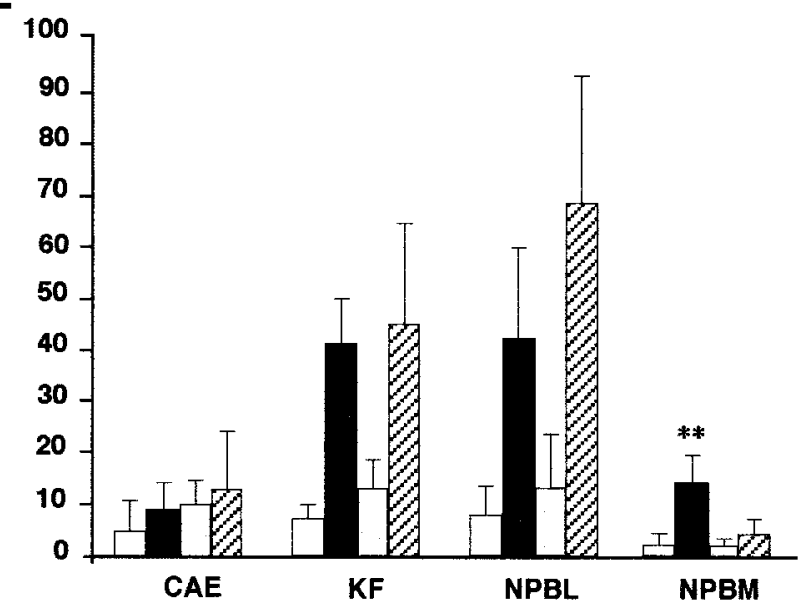

B

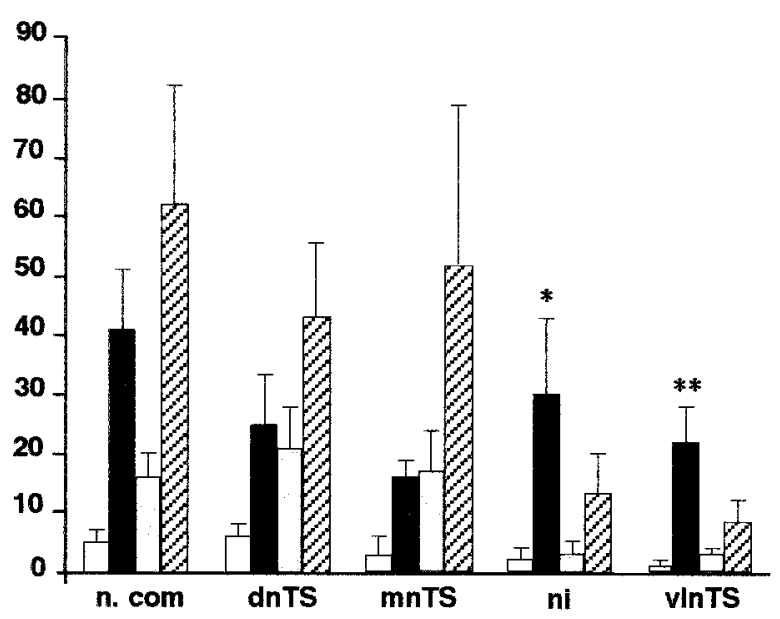

D

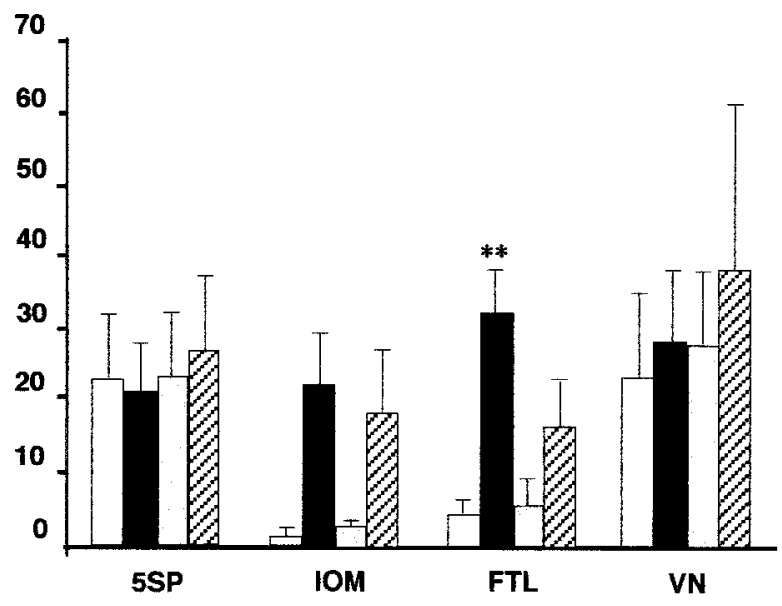

Figure 9. Numbers of Fos-like immunoreactive neurons for the four groups in various brainstem nuclei: $A$, dorsal vagal complex; $B$, nTS subnuclei; $C$, ventral medulla; $D$, other medullary regions; and $E$, pons. Histograms represent mean numbers of Fos-positive neurons with superimposed SD. Asterisks indicate significant $\left({ }^{*} p<0.05\right.$ and $\left.{ }^{* *} p<0.01\right)$ increases of Fos-positive neurons in coughing cats versus both control and stimulated-treated animals. Abbreviations are defined in legend to Figure 3.

FLI in stimulated-treated cats likely results from apnea, swallowing, salivation, or transient changes in vaso- and bronchomotor tones persisting after codeine administration. Hypertension can evoke FLI within the dorsomedial and caudal aspects of the nTS, the rostral ventrolateral medulla, the NPBL, and the KF of other species (Li and Dampney, 1992; Gieroba and Blessing, 1994; 
Miura et al., 1994). In addition, laryngeal afferents triggering swallowing terminate in various nTS subdivisions, and their activation could have reinforced the level of FLI in these subnuclei. However, none of the above reflexes elicited in stimulatedtreated cats (Fig. $1 B$ ) induce a level of FLI comparable to that observed in coughing animals.

\section{Brainstem areas involved in FC generation}

The most striking result of our study was the different pattern of FLI evoked in coughing animals compared with that in stimulated-treated ones. The selective Fos-like expression induced in discrete brainstem nuclei of coughing cats mapped neurons that could be involved in FC generation. In the dorsal medulla of coughing cats, FLI was enhanced in ni and vlnTS. We recently reported that inspiratory neurons in the vlnTS, i.e., the dorsal respiratory group (Bianchi et al., 1995), exhibit sustained activation during the inspiratory phase of FC (Gestreau et al., 1996). In addition, neurons in the vlnTS and ni are monosynaptically activated by laryngeal afferents (Bellingham and Lipski, 1992; Jiang and Lipski, 1992; Mifflin, 1993). Thus, both vlnTS and ni neurons may process laryngeal inputs causing FC. Reduced FLI in the ni and vlnTS subdivisions also suggests that codeine exerts its antitussive action by preventing the activation by laryngeal afferents of the second-order neurons of the cough reflex.

In the ventral medulla, FLI selectively induced in coughing cats overlapped the ventral respiratory group (VRG), a column of neurons associated with the RA, AMB, and RFN. All three nuclei contain many respiratory neurons distributing the central respiratory drive to both upper airway and thoracoabdominal respiratory-related muscles (Bianchi et al., 1995). VRG expiratory and inspiratory neurons, including interneurons and premotoneurons, fire during either the diaphragmatic or abdominal phases of coughing (or FC) with a higher frequency than during breathing (Jakus et al., 1985, 1987; Shannon et al., 1992; Oku et al., 1994). Therefore, activation of VRG neurons may explain the widespread FLI within the ventral medullary regions of coughing cats. Whether pharyngeal and laryngeal motoneurons form part of the VRG labeled neurons cannot be ascertained.

In the pons, a few Fos-positive neurons were observed in NPBM of coughing cats. This nucleus has been referred to as the pneumotaxic center, which promotes inspiratory termination (Bianchi et al., 1995). Direct projections from n.com to NPBM (Otake et al., 1992) could explain FLI induced in this pontine area.

Finally, the medial part of FTL and the internal division of LRN exhibited FLI after FC. Interestingly, these discrete parts of the medullary reticular formation are usually not associated with the respiratory central pattern generator (CPG). Fung et al. (1995) reported the recruitment of nonrespiratory-related units in the FTL during the aspiration reflex, a phenomenon possibly occurring during FC. A very similar pattern of FLI is present in the cat's reticular formation after vocalization (Jüergens and Lu, 1994), emesis (Miller and Ruggiero, 1994), and sneezing (Wallois et al., 1995); all of these motor activities involve the contraction of respiratory-related muscles. Therefore, activation of reticular neurons, as demonstrated by Fos immunocytochemistry, may be necessary for the motor program associated with cough and other nonrespiratory behaviors. However, the precise role of reticular neurons during cough remains to be investigated.

In conclusion, FC evokes a selective FLI in several brainstem areas, suggesting a crucial role for these structures in cough generation. This FLI overlapped not only dorsal and ventral brainstem areas containing dense populations of respiratory neurons but also the medial part of FTL and the internal division of LRN. Neurons of these reticular nuclei may be a necessary part of the cough CPG because they seem to be generally activated in other stereotyped behaviors involving respiratory muscles.

\section{REFERENCES}

Abbadie C, Besson J-M (1993) Effects of morphine and naloxone on basal and evoked Fos-like immunoreactivity in lumbar spinal cord neurons of arthritic rats. Pain 52:29-39.

Bellingham MC, Lipski J (1992) Morphology and electrophysiology of superior laryngeal nerve afferents and post-synaptic neurons in the medulla oblongata of the cat. Neuroscience 48:205-216.

Bereiter DA, Hathaway CB, Benetti AP (1994) Caudal portions of the spinal trigeminal complex are necessary for autonomic responses and display Fos-like immunoreactivity after corneal stimulation in the cat. Brain Res 657:73-82.

Berman AL (1968) The brainstem of the cat: a cytoarchitectonic atlas with stereotaxic coordinates. Milwaukee: University of Wisconsin.

Bianchi AL, Denavit-Saubié M, Champagnat J (1995) Central control of breathing in mammals: neuronal circuitry, membrane properties, and neurotransmitters. Physiol Rev 75:1-46.

Boissonade FM, Davison JS (1996) Effects of vagal and splanchnic nerve section on Fos expression in ferret after emetic stimuli. Am J Physiol 271:R228-R236.

Bolser D (1991) Fictive cough in the cat. J Appl Physiol 71:2325-2331.

Bonaz B, Plourde V, Taché Y (1994) Abdominal surgery induces Fos immunoreactivity in the rat brain. J Comp Neurol 349:212-222.

Borison HL (1989) Area postrema: chemoreceptor circumventricular organ of the medulla oblongata. Prog Neurobiol 32:351-390.

Brodal A (1943) The cerebellar connections of the nucleus reticularis lateralis (nucleus funiculi lateralis) in rabbit and cat: experimental investigations. Acta Psychiatr Neurol Scand 18:171-233.

Bucher K (1958) Pathophysiology and pharmacology of cough. Pharmacol Rev 10:43-58.

Chan RKW, Sawchenko PE (1994) Spatially and temporally differentiated patterns of c-fos expression in brainstem catecholaminergic cell groups induced by cardiovascular challenges in the rat. J Comp Neurol 348:433-460.

Cox RG (1994) Hypoxaemia and hypotension after intravenous codeine phosphate. Can J Anaesth 41:1211-1213.

Dragunow M, Faull R (1989) The use of c-fos as a metabolic marker in neuronal pathway tracing. J Neurosci Methods 29:261-265.

Ebersberger A, Anton F, Tölle TR, Zieglgänsberger W (1995) Morphine, 5-HT2 and 5-HT3 receptor antagonists reduce c-fos expression in the trigeminal nuclear complex following noxious chemical stimulation of the rat nasal mucosa. Brain Res 676:336-342.

Erickson JT, Millhorn DE (1991) Fos-like protein is induced in neurons of the medulla oblongata after stimulation of the carotid sinus nerve in awake and anesthetized rats. Brain Res 567:11-24.

Fung ML, Tomori Z, St-John WM (1995) Medullary neuronal activities in gasping induced by pharyngeal stimulation and hypoxia. Resp Physiol 100:195-202.

Gestreau C, Portillo F, Yousfi M, Puizillout JJ, Grélot L (1994) Brainstem distribution of c-Fos immunoreactivity following repetitive coughing in the decerebrate cat. Eur J Neurosci [Suppl 7] Abstr 95-01.

Gestreau C, Milano S, Bianchi AL, Grélot L (1996) Activity of dorsal respiratory group inspiratory neurons during laryngeal-induced fictive coughing and swallowing in decerebrate cats. Exp Brain Res 108:247-256.

Gieroba ZJ, Blessing WW (1994) Fos-containing neurons in medulla and pons after unilateral stimulation of the afferent abdominal vagus in conscious rabbits. Neuroscience 59:851-858.

Gogas KR, Presley RW, Levine JD, Basbaum AI (1991) The antinociceptive action of supraspinal opioids results from an increase in descending inhibitory control: correlation of nociceptive behavior and c-fos expression. Neuroscience 42:617-628.

Grélot L, Milano S (1991) Diaphragmatic and abdominal muscle activity during coughing in the decerebrate cat. NeuroReport 2:165-168.

Hammond DL, Presley R, Gogas KR, Basbaum AI (1992) Morphine or U-50,488 suppresses Fos protein-like immunoreactivity in the spinal cord and nucleus tractus solitarii evoked by a noxious visceral stimuli. J Comp Neurol 315:244-253.

Herdegen T, Kovary K, Leah J, Bravo R (1991) Specific temporal and 
spatial distribution of JUN, FOS, and Krox-24 proteins in spinal neurons following noxious transsynaptic stimulation. J Comp Neurol 313:178-191.

Hunt PS, Pini A, Evan G (1987) Induction of c-fos-like protein in spinal cord neurons following sensory stimulation. Nature 328:632-634.

Jakus J, Tomori Z, Stránsky A (1985) Activity of bulbar respiratory neurones during cough and other respiratory tract reflexes in cats. Physiol Bohemoslov 34:127-136.

Jakus J, Tomori Z, Stránsky A, Boselova L (1987) Bulbar respiratory activity during defensive airway reflexes. Acta Physiol Hungarica 70:245-254.

Jiang C, Lipski J (1992) Synaptic inputs to medullary respiratory neurons from superior laryngeal afferents in the cat. Brain Res 584:197-206.

Jüergens U, Lu C-L, (1994) C-fos expression in the brain of a new world monkey (Saguinus Fuscicollis) during long-lasting vocalization. Eur J Neurosci [Suppl 7] Abstr 97-30.

Kalia M, Mesulam MM (1980) Brain stem projections of sensory and motor components of the vagus complex in the cat: II. Laryngeal, tracheobronchial, pulmonary, cardiac, and gastrointestinal branches. J Comp Neurol 193:467-508.

Kasé Y (1980) Antitussive agents and their sites of action. Trends Pharmacol Sci 1:237-239.

Kasé Y, Wakita Y, Kito G, Miyama T, Yuizono T, Kataoka M (1970) Centrally-induced coughs in the cat. Life Sci 9:49-59.

Korecky B, Palecek F (1964) The assessment of respiratory response curves to carbon dioxide in drug evaluation. In: Drugs and respiration, Vol 11 (Aviado DM, Palecek F, eds), p 241. Oxford: Pergamon.

Korpas J, Tomori Z (1979) Cough and other respiratory reflexes. In: Progress in respiratory research, Vol 12 (Herzog H, ed), pp 1-336. Basel: Karger.

Kromer W (1988) Endogenous and exogenous opioids in the gastrointestinal motility and secretion. Pharmacol Rev 40:121-162.

Lantéri-Minet M, Weil-Fugazza J, De Pommery J, Ménétrey D (1994) Hindbrain structures involved in pain processing as revealed by the expression of c-Fos and other immediate early gene proteins. Neuroscience 58:287-298.

Li Y-M, Dampney RAL (1992) Expression of c-fos protein in the medulla oblongata of conscious rabbits in response to baroreceptor activation. Neurosci Lett 144:70-74.

Li Y-M, Dampney RAL (1994) Expression of Fos-like protein in brain following sustained hypertension and hypotension in conscious rabbits. Neuroscience 61:613-634.

Lucier GE, Egizii R, Dostrovsky JO (1986) Projections of the internal branch of the superior laryngeal nerve of the cat. Brain Res Bull 16:713-721.
Mifflin SW (1993) Laryngeal afferent inputs to the nucleus of the solitary tract. Am J Physiol 265:R269-R276.

Miller AD, Ruggiero DA (1994) Emetic reflex arc revealed by expression of the immediate-early gene c-fos in the cat. J Neurosci 14:871-888.

Miura M, Takayama K, Okada J (1994) Neuronal expression of Fos protein in the rat brain after baroreceptor stimulation. J Auton Nerv Syst 50:31-43.

Morgan JI, Curran T (1991) Stimulus-transcription coupling in the nervous system: involvement of the inducible proto-oncogenes fos and jun. Annu Rev Neurosci 14:421-451.

Otake K, Sasaki H, Ezure K, Manabe M (1989) Axonal trajectory and terminal distribution of inspiratory neurons of the dorsal respiratory group in the cat's medulla. J Comp Neurol 286:218-230.

Otake K, Ezure K, Lipski J, Wong She RB (1992) Projections from the commissural subnucleus of the nucleus of the solitary tract: an anterograde tracing study in the cat. J Comp Neurol 324:365-378.

Oku Y, Tanaka I, Ezure K (1994) Activity of bulbar respiratory neurons during fictive coughing and swallowing in the decerebrate cat. J Physiol (Lond) 480:309-324.

Pozzeto H, Traimer J (1962) Physiologie et physiopathologie de la toux. Poumon Coeur 18:393-406.

Presley RW, Menetrey D, Levine JD, Basbaum AI (1990) Systemic morphine suppresses noxious stimulus-evoked Fos protein-like immunoreactivity in the rat spinal cord. J Neurosci 10:323-335.

Ramon y Cajal S (1909) Histologie du système nerveux de l'homme et des vertébrés. Reprint (Azoulay L, translator). Madrid: Intituto Ramón Y Cajal.

Shannon R, Morris KE, Lindsey BG (1992) Medullary ventral respiratory group (VRG) neurons responses during fictive coughing. Soc Neurosci Abstr 58.6.

Soulier V, Gestreau C, Borghini N, Dalmaz Y, Cottet-Emard JM, Péquignot JM (1997) Peripheral chemosensitivity and central integration: neuroplasticity of catecholaminergic cells under hypoxia. Comp Biochem Physiol 78-86.

Tölle TR, Schadrack J, Castro-Lopes JM, Evan G, Roques BP, Zieglgänsberger W (1994) Effects of Kelatorphan and morphine before and after noxious stimulation immediate-early gene expression in rat spinal cord neurons. Pain 5:103-112.

Wallois F, Gros F, Masmoudi K, Larnicol N (1995) C-fos-like immunoreactivity in the cat brainstem evoked by sneeze-inducing air puff stimulation of the nasal mucosa. Brain Res 687:143-154.

Yousfi-Malki M, Puizillout JJ (1994) Induction of Fos-like protein in neurons of the medulla oblongata after electrical stimulation of the vagus nerve in anesthetized rabbit. Brain Res 635:317-322. 